\title{
USING BIG DATA AND GEOSPATIAL APPROACHES IN EVALUATING ENVIRONMENTAL INTERVENTIONS
}

\author{
Anupam Anand and Geeta Batra
}

\section{Introduction and background}

Big data is commonly distinguished by volume, velocity, and variety (Goodchild 2013). A large portion of these data is georeferenced and therefore carries spatial information. This subset of spatial data is referred to as "big (geo) data." Geospatial data and methods, in particular the application of satellite remote sensing, have been used in the monitoring and assessment of environmental processes for the past four decades, based on its ability to provide synoptic, time-series data for various earth system processes (Spitzer 1986; Melesse et al. 2007; Awange and Kyalo Kiema 2013). However, its application in the field of evaluation to assess the relevance and performance of environmental programs has gained traction in the last two decades. Evaluators typically used GIS mainly for visualization during early applications in evaluation. Renger et al. (2002) describe how GIS data and analysis are used for visualization, change detection, and in conjunction with other evaluation data. Evaluators have also discussed the usefulness of spatial data for measuring baselines, outputs, and in observing the results of interventions over time (Azzam 2013; Azzam and Robinson 2013). Quasi-experimental designs (Ferraro and Pattanayak 2006; Andam et al. 2008; Buchanan et al. 2018) leveraging geospatial data were used to conduct impact evaluations in forestry and biodiversity interventions. Recently, geospatial analysis has also been used in randomized control trials (Jayachandran et al. 2017).

Further, the role of geospatial science is increasingly being recognized by several major environmental and development policy conventions and institutions as countries move toward more evidence-based policy decisions and practice. For example, the United Nations Convention to Combat Desertification (UNCCD) has endorsed the use of indicators obtained from remote sensing to monitor progress toward reversing and halting the degradation and desertification of land (Minelli 
et al., 2017). The United Nations Framework Convention on Climate Change (UNFCCC) and the Convention on Biological Diversity (CBD) also endorse the use of objective indicators, many of which are derived through geospatial methods.

Three main factors have influenced the uptake of geospatial data, and the "new data revolution." First, there has been a remarkable increase in the availability of geospatial data. Currently, there are more than 1950 operating satellites in space (World Economic Forum 2019), of which 382 were launched in 2018 (UNOOSA). Private investments in space technology have also increased substantially and such investment increased from US $\$ 0.5$ billion in 2011 to US $\$ 5.8$ Billion in 2019, making 2019 the most significant year on record for investment in space (Space Investment Quarterly: Q4 2019).

Second, the availability and accessibility to high-performance computational power have made such complex data sets efficient and affordable to process. Cloudbased platforms such as Google Earth Engine, the Sentinel Hub, ESRI, Amazon Web Services, etc. have made the processing and analysis of "big" data possible at a planetary scale (Lech et al. 2018). Moreover, recent developments in statistics and data science have led to novel algorithms based on the principles of machine learning and artificial intelligence that are "data-hungry" and therefore work efficiently with high volume and complex data structures.

The third factor is the growing demand for reliable and transparent data for various purposes - for business intelligence, environmental management, infrastructure planning, navigation, disaster risk management, etc. Global initiatives such as SDGs with a proposed list of about 230 indicators have further provided opportunities to seek data that is globally consistent and locally relevant.

Geospatial data and methods can help address common methodological challenges observed in evaluation, such as the lack of baseline data, sampling bias, difficulties in selecting appropriate counterfactuals, and account for the impact of multiple scales and contexts on processes and interventions. These new data and methods can complement other commonly used quantitative and qualitative evaluation approaches. Therefore, the timing is right for us to leverage the availability of such data, which can potentially change the way we collect evaluative evidence on environmental and other development interventions.

In the next section of this chapter, we illustrate the usefulness of geospatial data in evaluation through examples of specific applications to assess the relevance and impact of environmental interventions by the Global Environment Facility (GEF).

\section{Applications of geospatial analysis in environmental evaluation}

The Independent Evaluation Office (IEO) of the GEF is responsible for assessing the performance and effectiveness of GEF interventions. The IEO has applied geospatial methods to complement other evaluation methods to answer pertinent evaluation questions on the relevance, effectiveness, efficiency, and sustainability of 
GEF interventions, in three focal areas: biodiversity, land degradation, and climate change. We present a few examples which demonstrate the application of remote sensing and geospatial approach in these thematic areas to answer questions based on standard evaluation criteria.

\section{Case 1. Geospatial analysis to assess the relevance of GEF support to protected areas}

Support to protected areas is a core component in strategies for biodiversity conservation (DeFries et al. 2005). The Aichi Targets and the associated Target 11 aspire to effectively and equitably manage $17 \%$ of terrestrial and inland water, and $10 \%$ of coastal and marine areas by 2020 , thereby signifying the importance of protected areas in biodiversity conservation and management of ecosystem services. As the financial mechanism for the UN CBD, the GEF's Strategy is consistent with the CBD's Strategic Plan and is reflected in its support to protected areas over the past 26 years. Between 1991 and 2015, the GEF provided $\$ 3.4$ billion in grants to 618 projects, matched by $\$ 12.0$ billion in co-financing, to help protect almost 2.8 million $\mathrm{km}^{2}$ of the world's non-marine ecosystems (GEF IEO 2016a).

Setting area-based targets for conservation through the establishment and management of protected areas is crucial. However, to maximize the return from conservation investments, interventions should be designed for ecologically representative biodiversity-rich sites with high biodiversity values. This is not always the case; for example, 49\% of Important Bird Areas and 51\% of Alliance for Zero Extinction sites for biodiversity conservation remain unprotected. However, the GEF biodiversity strategy prioritizes the conservation of protected areas based on significant and endemic biodiversity. Hence, in the evaluation of GEF Support to Protected Areas and Protected Area Systems (GEF IEO 2016a), conducted in collaboration with the IEO of the United Nations Development Programme (UNDP), we used geospatial analysis to assess the relevance of GEF interventions at global, country, and site levels. This impact evaluation also assessed the conservation outcomes as well as other co-benefits.

We carried out a spatial overlay analysis to determine the biodiversity significance of GEF-supported protected areas. The analysis involved a feature overlay of the GEF-supported protected areas with the areas of significant biodiversity presence and conservation importance such as Key Biodiversity Areas (KBAs) and Ramsar sites. The analysis demonstrated that $58 \%$ of GEF-supported protected areas were located in KBAs; 31\% met other conservation designations such as a Ramsar site, a WWF priority area, a Conservation International biodiversity hotspot, an Alliance for Zero Extinction site, or a U.N. heritage site; 11\% of GEF-supported protected areas were significant at the local or national level from a country perspective (Figure 5.1). The overall results from this study provided evidence that the GEF was allocating its resources into globally significant sites with high biological diversity or "hot spots." 


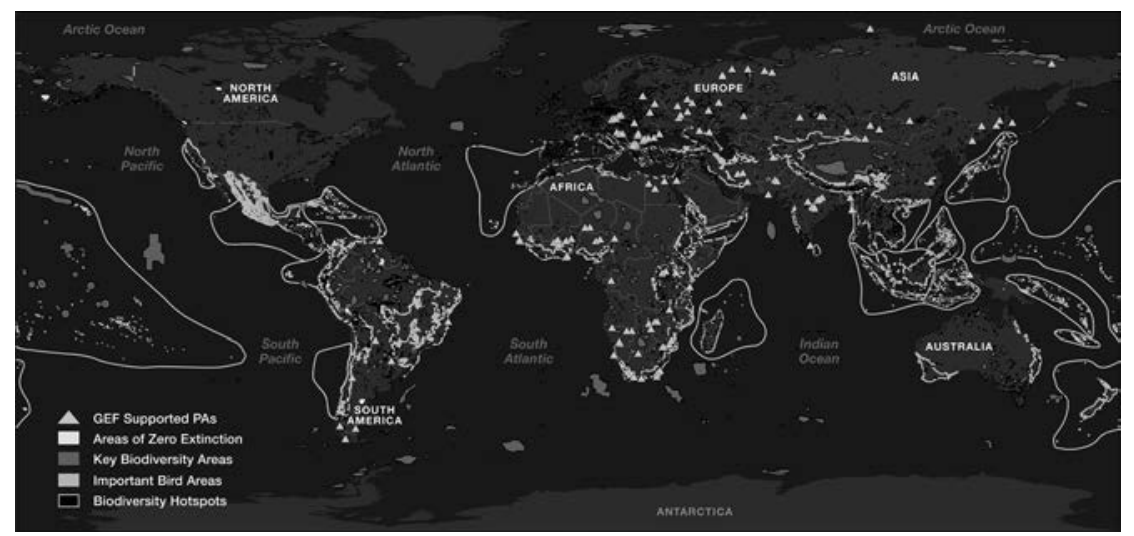

FIGURE 5.1 Globally Distributed Gef-Supported Protected Areas were Overlaid with Sites of Conservation Importance

\section{Case 2. Geospatial analysis to assess socio-economic co-benefits of GEF-supported interventions}

Despite extensive research over the past few decades, evidence on the socio-economic impacts of initiatives designed to influence environmental outcomes remain limited and inconsistent (Spitzer 1986; Melesse et al. 2007; Awange and Kyalo Kiema 2013). Studies that have tried to address this gap have various limitations, such as the varying nature of co-benefits attributable to environmental initiatives and the data and approaches used to assess co-benefits. The difference in methodological approaches and in temporal and spatial scales also presents a challenge in drawing general conclusions from these assessments (Naidoo et al. 2019; Alpízar and Ferraro 2020).

More recently, studies utilizing geospatial analysis have demonstrated how satellite-based data sources can be leveraged for assessing environmental and socioeconomic outcomes. In the case of the GEF, the socio-economic co-benefits of its environmental interventions had never been evaluated before. Building on recent development in research and impact evaluation, the IEO conducted an evaluation to estimate the global and local level socio-economic co-benefits of GEF initiatives to support the environment.

We used a geospatial approach to determine the socio-economic benefits associated with GEF-supported interventions in Sustainable Forest Management (SFM). Since its establishment in 1992, the GEF has provided support to improve the sustainability of forestry resources to increase environmental benefits and deliver socioeconomic co-benefits; yet these co-benefits had never been measured. Through this evaluation, we assessed the impacts of GEF-supported SFM interventions on biophysical and ecological variables, co-benefits measured in terms of socio-economic indicators, and the estimated monetary values of ecosystem services applying the principle of natural capital accounting. 


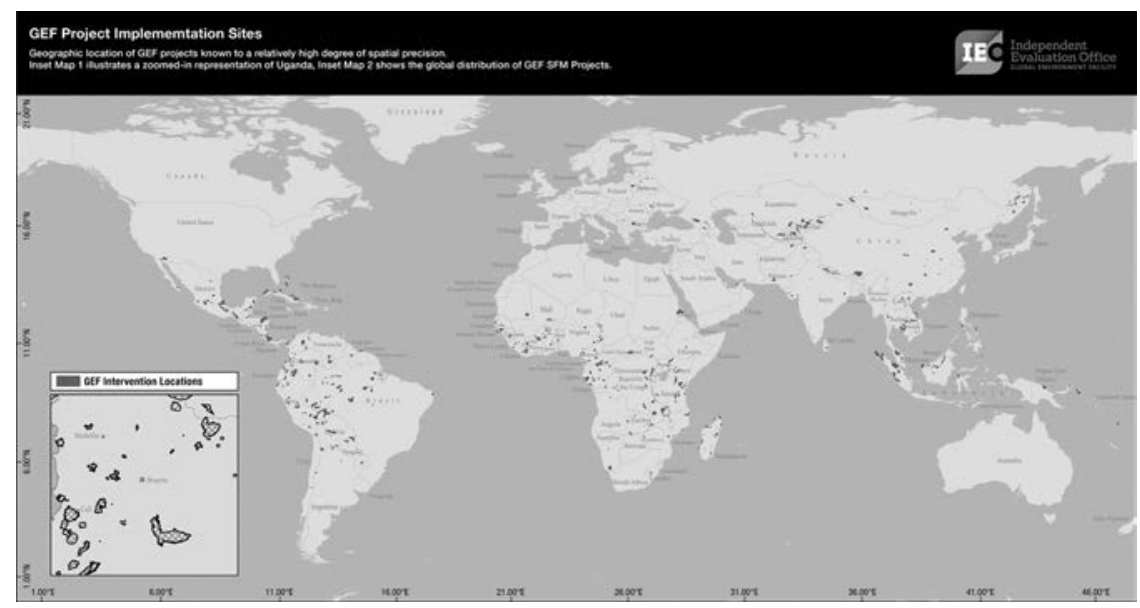

FIGURE 5.2 Geocoded Location Information for GEF Project Implementation Areas Inset Map 1 (Bottom) Illustrates a zoomed-in representation of Colombia

Data used included the geographic locations of GEF SFM projects and measurements on environmental outcomes based on indicators suggested by the Convention on Biological Diversity (CBD, 2016) and the United Nations Convention to Combat Desertification (UNCCD, 2015). To examine the socio-economic effects of GEF interventions, we used both a portfolio-wide approach (Figure 5.1) (based on night light activity $^{1}$ ), as well as a single-country case study. The case study was in Uganda, where data from the World Bank's Living Standards Measurement Survey (LSMS) provided in-country household survey information.

A causal tree approach helped us understand the factors which have a significant effect on deforestation, vegetation density, and nighttime lights and to estimate the above-ground carbon sequestration attributable to each GEF SFM project location. Air temperature, precipitation, population, road networks, etc. were some of the variables included in the causal tree, several of which were significantly associated with the outcomes. The evaluation approach then compared geospatial regions with GEF projects with those regions with no GEF projects based on a set of similar attributes, and the differences in outcome were used to estimate the impact of the GEF intervention. Details of this approach can be found in Annex of the report (GEF IEO 2019a), as well as in the value for money analysis of land degradation projects of the GEF (GEF IEO 2016b).

The portfolio level global-scope analysis suggested a small, positive impact on socio-economic benefits indicated by nighttime light intensity. We found evidence that projects implemented since 2010 demonstrated a positive effect on nighttime lights $(+0.24)$, a proxy for economic development, and which was not discernible in preceding periods. In the absence of precise geographic information, these findings may represent an under-estimate of the actual impacts across the GEF SFM portfolio since locations without any recorded high precision geographic data in 
project descriptions were not included in our analysis. We realized that the results from the nighttime lights at the portfolio level were not clear, suggesting the need for local-level data and analysis. Nighttime lights limit accuracy in measurement in areas with very low light intensity such as forest environments which represent the areas where GEF supports SFM initiatives.

We conducted a local-scale analysis in Uganda using survey data to fill the gap in the portfolio-level analysis and to explore further the impact of GEF SFM projects on socio-economic outcomes, by assessing the correlation between household assets and the presence of GEF interventions. We divided Uganda into an area-based grid consisting of smaller multiple units 10 square kilometers each, for which all satellite and survey information was generalized for analysis (Figure 5.3). For every 10 square kilometers, as seen in Figure 5.3, the distance to the nearest GEF SFM project was calculated. Further, total household assets in 2009 and 2011 were calculated using the LSMS data to detect the impact of GEF projects on proximate (within $50 \mathrm{~km}$ ) households. The local analysis helped limit the interpretation to areas with significant degrees of change that are unlikely to be attributable to error. Further details of this approach are in the original evaluation report (GEF IEO 2019a).

The results showed that GEF SFM projects are associated with an increase in household assets. By matching LSMS locations proximate to GEF interventions to those further away from GEF interventions, we found that GEF SFM projects

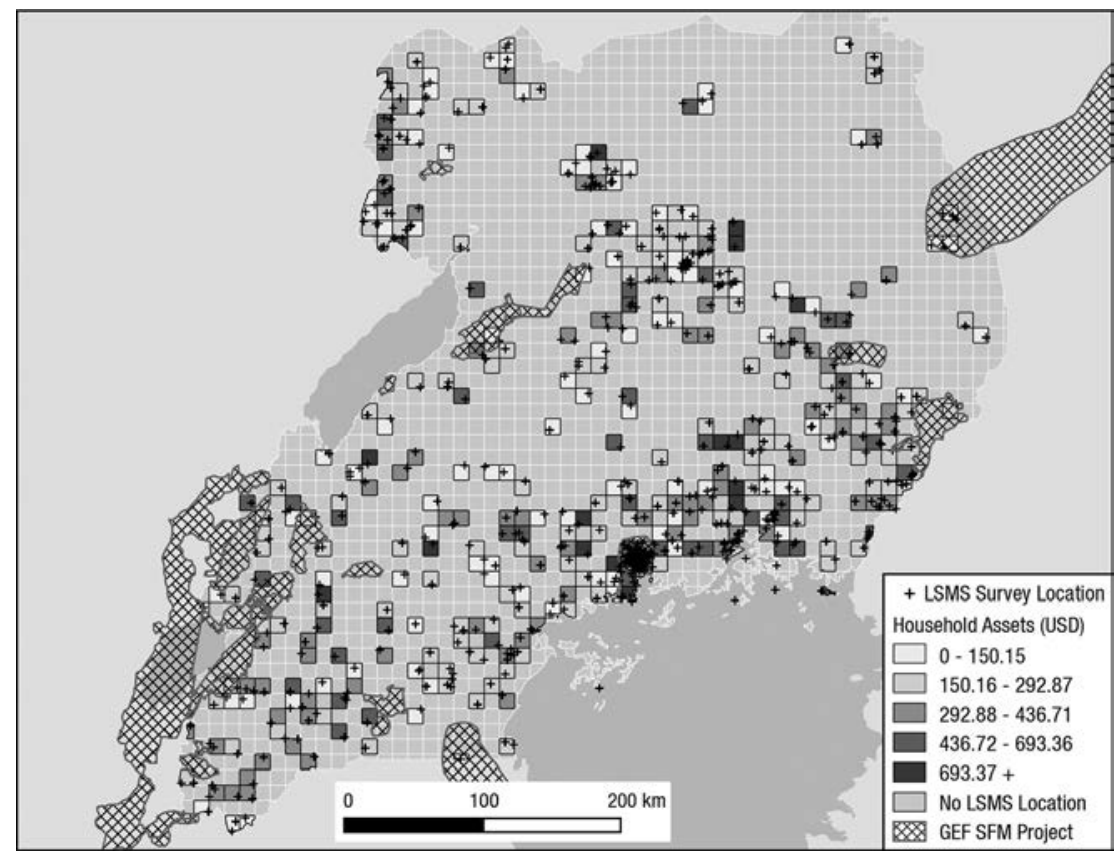

FIGURE 5.3 Data Used in the Uganda Case Study. The Light Gray Shade Indicates Areas with No LSMS Data, Hashed Areas Indicate GEF SFM Projects, and Square Grids with Black Boundaries Indicate Areas where LSMS Data was Available 
are associated with an increase in household assets between $\$ 163$ and $\$ 353$ (within 40-60 km respectively). The study showed that households proximate to a GEF implementation site tended to have, on average, an increase in assets approximately $\$ 310$ (within $50 \mathrm{~km}$ ) higher than those not proximate to a GEF implementation site.

\section{Case 3. Geospatial analysis in measuring the sustainability of environmental outcomes in the Ba Be protected area}

Donors are increasingly interested in the long-term sustainability of project outcomes, and not just in the attainment of outcomes. An IEO evaluation found that the outcomes of several GEF projects are sustained during the post-completion period, and a higher percentage of projects achieve environmental stress reduction than had been determined at completion (GEF IEO 2019b). Assessing the sustainability of outcomes continues to be a challenge since sustainability at project closure is assessed as a "likelihood of sustainability" and is seldom re-evaluated during the post-completion period using primary data sources. It takes time to achieve sustainability of outcomes, and it takes significant resources to measure sustainability at post completion. Geospatial methods are useful in evaluating post completion sustainability efficiently. In an IEO study, using geospatial tools, we assessed the long-term sustainability of environmental outcomes of a GEF-supported protected area in Vietnam, for biodiversity conservation - "Promotion of Sustainable Forest and Land Management in the Vietnam Uplands."

One of the main sites of the project was the $\mathrm{Ba} \mathrm{Be} / \mathrm{Na}$ Hang Conservation Complex in the hilly Bac Kan Province in north-easternVietnam rich in biodiversity. The park supports the population of several nationally and globally threatened species. It also supports the only significant natural mountain lake in Viet Nam - a RAMSAR site - which is the most important wetland in the country's protected area system. Agriculture, forestry, and livestock production are the primary sources of income and sustenance. The main threat to the biodiversity in the area is the fragmentation of habitat, conversion of forest land for large-scale infrastructure and agriculture, livestock grazing, illegal hunting, and overuse for non-timber forest products. The project focused on working with rural upland communities for better management of land and forests: interventions included improved systems for animal husbandry and conservation of sloping areas, bio-energy applications; a voluntary payment for ecosystem services and small-scale private tourism enterprise development, participatory approaches to forest land allocation and protection; and, support for the implementation of protected area management plans.

We primarily used satellite-based data to assess the sustainability of environmental outcomes. Our analysis focused on the trends in the change of forest cover and vegetation productivity in Ba Be National Park (Figure 5.4). We compared the loss in forest cover for different periods (before, during, and after the post-project) to those in areas outside the protected area, as well as with the overall national trends in forest cover loss. Remote sensing was used to regenerate the baselines as well as measure environmental outcomes. 

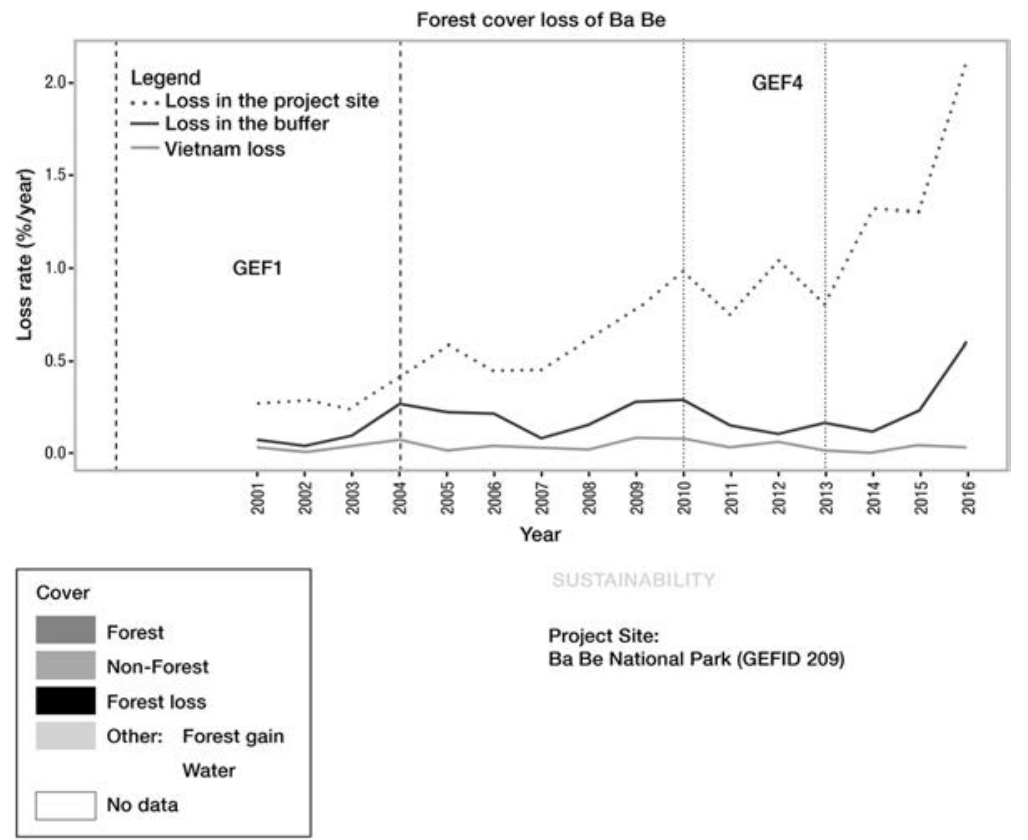

SUSTAINABILITY

Project Site:

Ba Be National Park (GEFID 209)

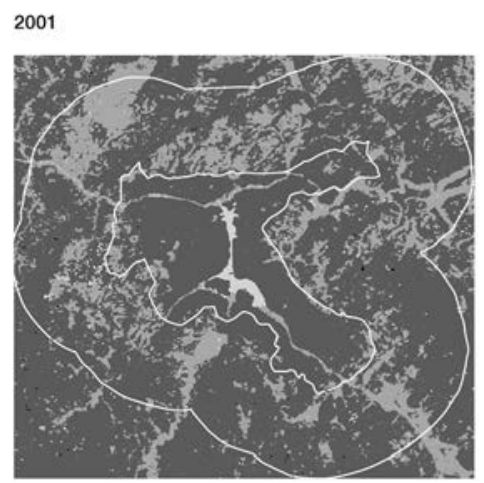

2005

2010
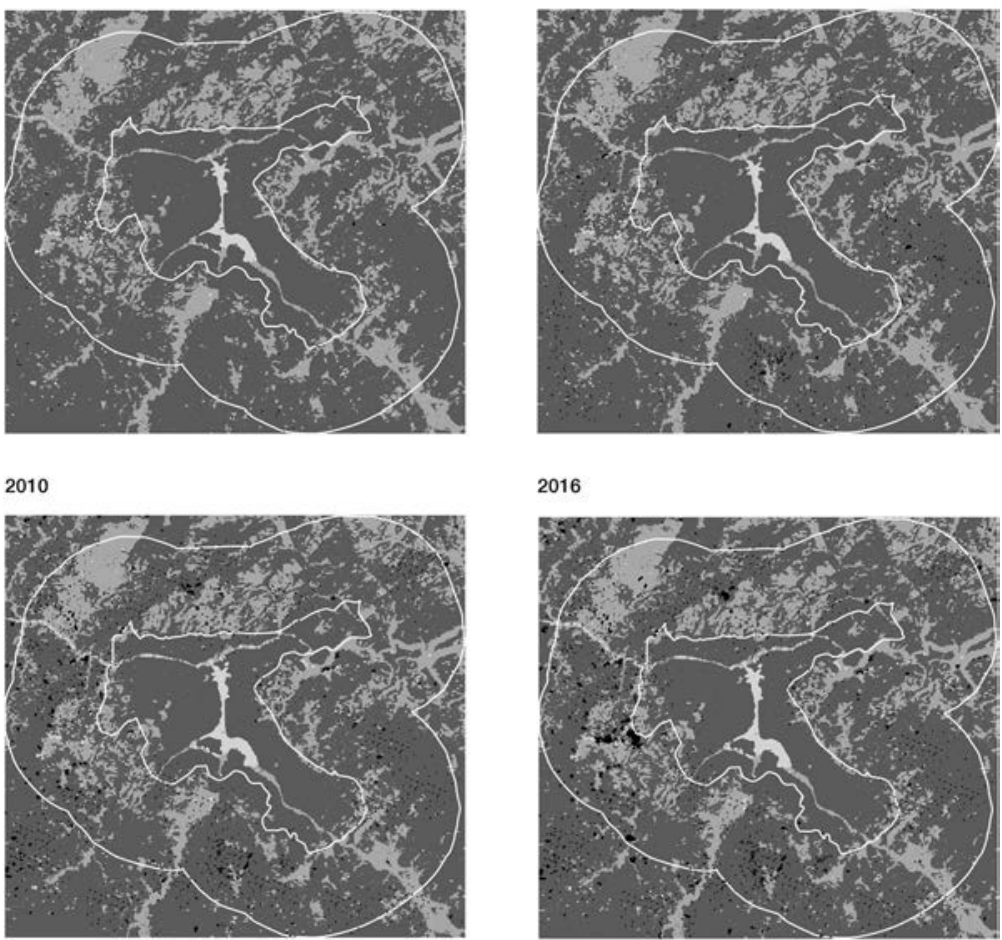

2016

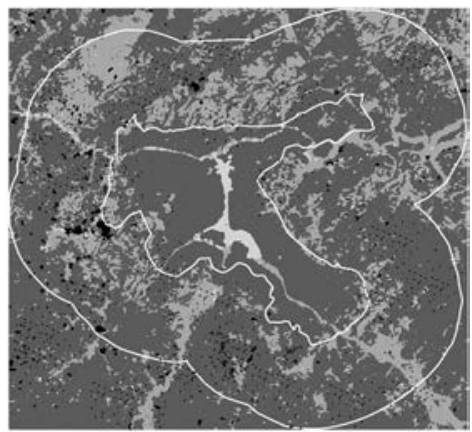

FIGURE 5.4 Trends and Comparison: Forest Loss Did Not Increase Despite an Unprecedented Increase in the Buffer and at Country Level 
The findings from the remote sensing analysis showed that forest cover in $\mathrm{Ba} \mathrm{Be}$ forest was maintained for several years after project completion. The forest loss in Ba-Be did not increase despite an unprecedented increase in forest loss in the adjacent area and more broadly at the country level. The post-project loss for the protected area was $0.1 \%$ compared to $0.55 \%$ in the buffer area and $2 \%$ at the national level in 2016, three years after project completion. Interviews with project staff and some beneficiaries indicated that project outcomes were sustained by community participation in project design and implementation including buy-in from local communities, attention to income generation activities, and continued support from provincial governments.

\section{Case 4. Geospatial analysis in ecological forecasting in Kenya}

An important decision for any multilateral institution such as the GEF is where to allocate scarce resources with the objective of maximizing overall environmental benefits. We partnered with the NASA DEVELOP team housed at Goddard Space Flight Center) to first measure land cover changes in GEF-supported protected areas in Kenya, and then developed a forecasting framework to estimate the future changes in land cover and carbon sequestration benefits, as returns on GEF investments.

\section{GEF supported protected areas in Kenya}

In Kenya, GEF projects have supported activities in approximately nineteen protected areas. These projects were accurately identified through the review of project documents. The protected areas spread over an area of $5,035 \mathrm{~km}^{2}$ with a broad range of land cover types and designations, including montane forests, coastal mangrove forests, deserts, grasslands, and shrubs. We examined twelve of the terrestrial protected areas (Figure 5.5) comprising two national parks, one marine national reserve, five forest reserves, three national reserves, and a community conservancy. The largest protected areas is Mount Kenya NP $\left(2,714.5 \mathrm{~km}^{2}\right)$, and the smallest is Mrima Forest Reserve $\left(3.9 \mathrm{~km}^{2}\right)$. The study timeframe covered two time periods representing the past and the future: 1995-2016 and 2020-2030.

Deforestation is a major environmental issue that is detrimental to biodiversity conservation and increases the threat to the number of endangered species facing extinction (Brooks et al. 2006). Kenya loses an average of 12,000 hectares (ha) of forest and 33,500 ha of open woodland per year, equivalent to an annual loss of 2 million metric tons of carbon, with agriculture, and public or private development projects causing the most deforestation (KFS 2010).

We used NASA Earth observations for the remote sensing analysis to assess the effectiveness of PAs throughout Kenya for the study period of 1995-2016. Landsat 5 TM, Landsat 7 ETM+, and Landsat 8 OLI Level 1 products were acquired through Google Earth Engine (GEE). This is a cloud computing system that is open for non-commercial use. We used Landsat images because of their extensive historical 


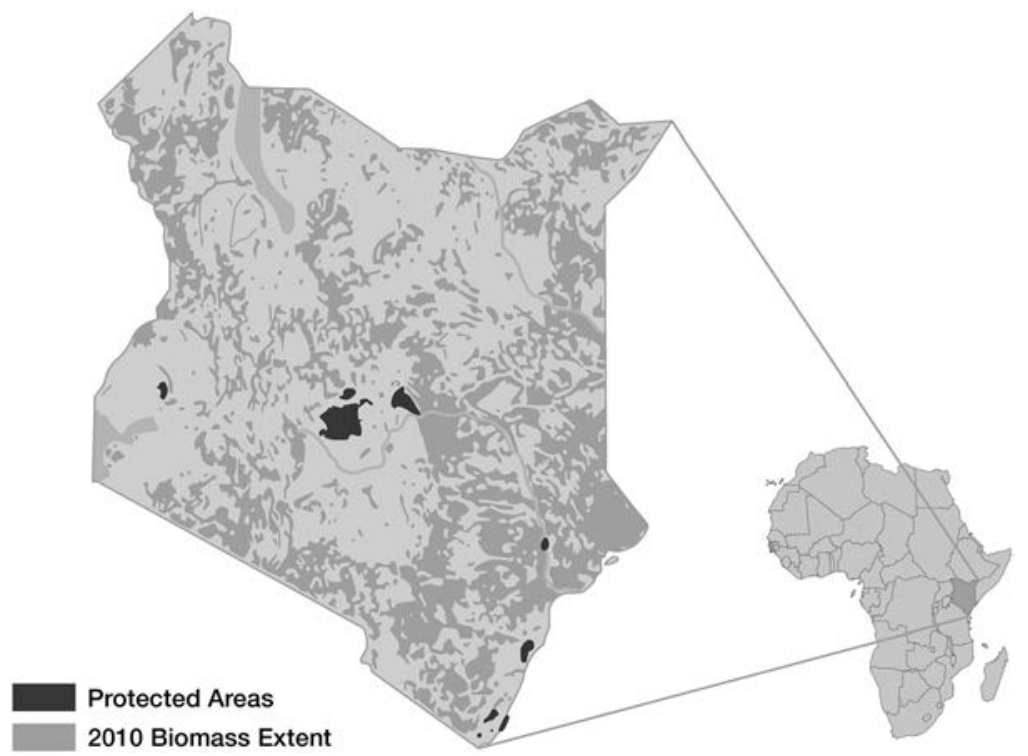

FIGURE 5.5 Study Area Map of the 12 PAs within Kenya Included in the Analysis

archive, open access, and suitable spatial resolution to analyze both large and small protected areas. We used Google Earth Engine for data acquisition and analysis. Freely available ancillary data sets were used for data on variables including temperature and precipitation, roads and waterways, human and livestock density estimates, and digital elevation, to project future land cover changes.

Carbon stock estimation tools are used for measuring the carbon balance and for estimating the likely greenhouse gas mitigation benefits as a result of project interventions. The most widely used carbon stock estimation tool is EX-ACT (EX-ante Appraisal Carbon-balance), a land-based accounting system developed by FAO. EX-ACT is a useful, cost-effective tool to measure carbon stocks and stock changes per unit of land and requires minimum data inputs. It is used for ex-ante assessments of the impact of agriculture and forestry interventions on carbon-balance. The tool helps to estimate economic and climate change mitigation benefits and thereby assists in prioritizing project activities.

Although tools such as EX-ACT are valuable for ex-ante measurements and analysis, and are easy to learn and deploy, these tools have certain limitations. They are not spatially explicit, their use is limited in identifying areas for interventions, and they do not account for contextual factors driving land use and land cover change. The primary input for these tabular models is area and type of land cover pre-intervention mainly derived from official records or information from processed satellite imagery. The main output of the tool is limited to carbon balance (GHGs) expressed in terms of $\mathrm{tCO} 2 \mathrm{e} / \mathrm{ha}$ and year resulting from project activities.

Spatially explicit ecological forecasting models address the limitations of, and complement appraisal systems such as Ex-ACT.The primary inputs for such models 
are land cover maps that are often produced within the same suite of tools that take raw satellite data or readily available classified land cover data. The land cover data generated can also serve as baseline data for other simple carbon balance tools. This approach also provides the capability to model and estimate future land cover change, based on the factors driving the change.

For our study, we used land-use change analysis, ecological forecasting, and ecosystem service estimation in terms of carbon stocks. Carbon stock was calculated using the national and regional coefficient as per the IPCC guidelines. Additionally, a mixed-methods approach combining remote sensing with field validation visits to project sites around Mount Kenya provided us with an in-depth review of the GEF-funded projects at multiple spatial and temporal scales.

At the Kakamega Forest Reserve site, our results showed that vegetated land cover had increased between 1999 and 2015 (Figure 5.6). The annual average Normalized Difference Vegetation Index (NDVI - middle panel, Figure 5.6) illustrates the increasing reflectance of near-infrared light, consistent with increasing "greenness" of the vegetated surfaces. We found that within Kakamega, areas that were previously mainly agricultural have been transitioning back to forest. Our results also found that forested areas have noticeably expanded, particularly in the southern half of the forest reserve, further confirmed through the visit to the site. Shrub has also expanded into previously non-vegetated areas along the western edge of the forest. As reforestation occurs, more plant biomass is accumulated in the above-ground stocks. The above-ground carbon estimates in the Kakamega Forest Reserve increased throughout the study period and in the projections for 2020 and 2030 as well. This carbon sequestration (bottom panel, Figure 5.6) reflects the additional co-benefits from the biodiversity project.

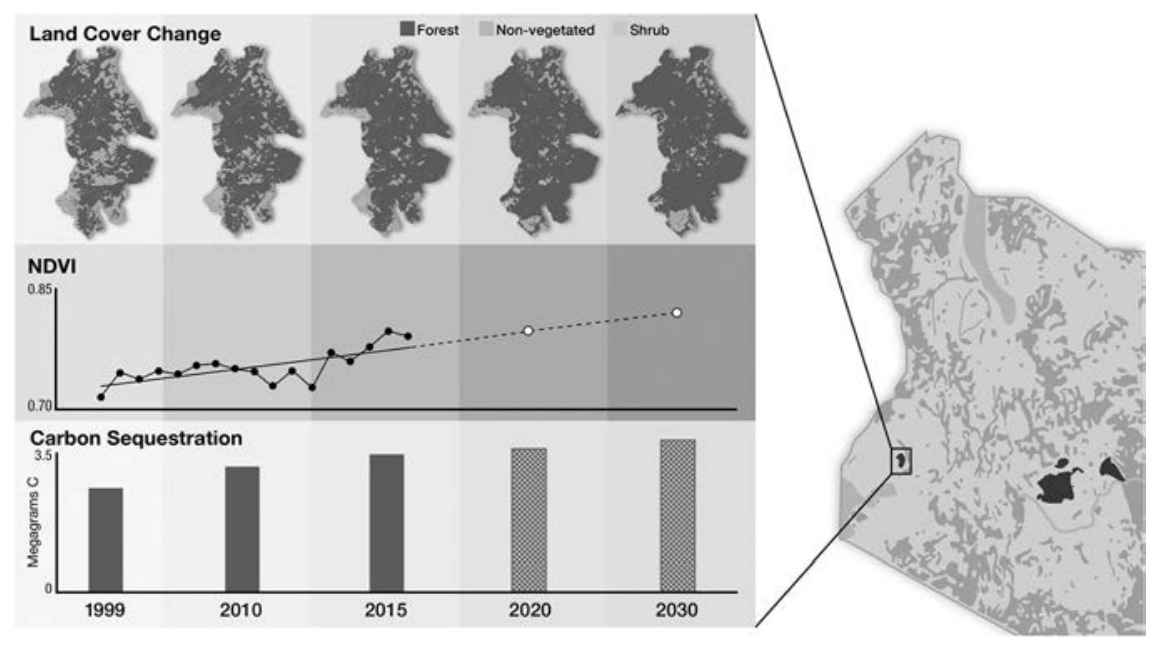

FIGURE 5.6 Land Cover Classifications for the Reserve Were Produced Using Landsat Imagery and Show the Progression of Vegetation for 1999, 2010, and 2015. The Forest Reserve Experienced Revegetation Following GEF-Funded Projects 


\section{Conclusion}

The cases presented in this chapter demonstrate the broad applications and advantages in using recent big data sets, methodologies, and computing platforms in evaluating the outcomes of environmental interventions. In the protected area evaluation presented in case study 1, we utilized Google's cloud computing platform using forest cover data (Hansen et al. 2013), which reduced the processing time significantly. In assessing the socio-economic co-benefits of GEF-supported interventions in SFM, we applied machine learning algorithms driven by geospatial data and econometric analysis, which allowed us to work with a high volume of data, and also provided us with insights into the factors associated with the outcomes. To evaluate the outcome sustainability of GEF interventions around $\mathrm{Ba} \mathrm{Be}$, we used decades of dense time-series data to assess the results and their sustainability. The IEO experience is based on evaluations conducted on environmental interventions; however, the approaches discussed here are applicable across a broad range of evaluation topics including disaster risk management, infrastructure and urban development.

Geospatial tools have greatly enhanced our ability to evaluate efficiently and cost-effectively at project, national, global, and ecologically meaningful scales. Big data from satellites are capable of revealing patterns that are not otherwise apparent. The results of our analysis are reproducible and have generated an objective evidence base while complementing other evaluation methods. We have also used geospatial tools in disseminating evaluation results through both static and interactive dynamic maps and visualizations. These innovative approaches to presenting and communicating evaluation results has made a significant difference in conveying complex information in a more lucid and efficient way.

With the increase in the type, volume, and availability of data, geospatial tools have presented new opportunities to access quantitative information on environment and development interventions and analyze their impacts. Technical skills, high computing capacity, and multidisciplinary expertise are needed to analyze and interpret data and results. The accuracy and reliability of contextual variables often vary widely across countries and sites, so geospatial approaches need to be complemented by field verification and other appropriate methods to interpret the data and to be able to provide qualitative insights to answer the "how" and "why." Some of the data and resource constraints in using geospatial approaches may be addressed through collaborations with institutions that have access to big data and the required infrastructure for use.

As the field of big geodata continues to advance, evaluators will need to explore innovative technologies such as blockchain, artificial intelligence, deep learning, the Internet of Things and computational social science, alongside traditional evaluation methods. Geospatial data and analysis offer an efficient and complementary approach to monitoring and evaluating new and increasingly complex evaluative topics and questions. The potential for mixed-method and multi-method approaches drawing upon different disciplines is immense, and we in the evaluation community have just embarked on this exciting journey. 


\section{Acknowledgments}

The authors gratefully acknowledge the role of the IEO partners - the Global Land Cover Facility at the University of Maryland AID DATA and NASA DEVELOP, AidData and the College of William and Mary, who contributed to the various evaluations presented in this chapter. The material presented in the case studies is based upon completed evaluations.

\section{Note}

1 Night lights are used as a proxy for socio-economic growth as studies have demonstrated that night time lights is highly correlated with economic activity, population, and establishment density (Mellander et al. 2015).

\section{References}

Alpízar, F. and Ferraro, P.J. (2020), “The environmental effects of poverty programs and the poverty effects of environmental programs: The missing RCTs", World Development, Vol. 127, p. 104783.

Andam, K.S., Ferraro, P.J., Pfaff, A., Sanchez-Azofeifa, G.A. and Robalino, J.A. (2008), "Measuring the effectiveness of protected area networks in reducing deforestation", Proceedings of the National Academy of Sciences, Vol. 105 No. 42, pp. 16089-16094.

Awange, J.L. and Kyalo Kiema, J.B. (2013), "Environmental monitoring and management", in Awange, J.L. and Kyalo Kiema, J.B. (Eds.), Environmental Geoinformatics: Monitoring and Management, Springer Berlin Heidelberg, Berlin, Heidelberg, pp. 3-16.

Azzam, T. (2013), "Mapping data, geographic information systems", New Directions for Evaluation,Vol. 2013 No. 140, pp. 69-84.

Azzam, T. and Robinson, D. (2013), "GIS in evaluation: Utilizing the power of geographic information systems to represent evaluation data", American Journal of Evaluation, Vol. 34 No. 2, pp. 207-224.

Brooks, T.M., Mittermeier, R.A., Fonseca, G.A.B. da, Gerlach, J., Hoffmann, M., Lamoreux, J.F., Mittermeier, C.G., et al. (2006), "Global biodiversity conservation priorities", Science, Vol. 313 No. 5783, pp. 58-61.

Buchanan, G. M., Parks, B. C., Donald, P. F., O’Donnell, B. F., Runfola, D., Swaddle, J. P., Tracewski, L., \& Butchart, S. H. M. (2018). The local impacts of World Bank development projects near sites of conservation significance. The Journal of Environment $\mathcal{E}$ Development, 27(3), 299-322.

DeFries, R., Hansen, A., Newton, A.C. and Hansen, M.C. (2005), "Increasing isolation of protected areas in tropical forests over the past twenty years", Ecological Applications, Vol. 15 No. 1, pp. 19-26.

Ferraro, P.J. and Pattanayak, S.K. (2006), "Money for nothing? A call for empirical evaluation of biodiversity conservation investments”, PLoS Biol,Vol. 4 No. 4, p. e105.

GEF IEO (2016a), Impact Evaluation of GEF Support to Protected Areas and Protected Area Systems, Washington, DC, Global Environment Facility Independent Evaluation Office. (http://www.gefieo.org/evaluations/impact-evaluation-gef-support-protectedareas-and-protected-area-systems-pas-2016)

GEF IEO (2016b), Value for Money Analysis for GEF Land Degradation Projects, Washington, DC, Global Environment Facility Independent Evaluation Office. (http://www.gefieo. org/evaluations/value-money-analysis-gef-land-degradation-projects-2016) 
GEF IEO (2019a), Value for Money Analysis of GEF Interventions in Support of Sustainable Forest Management, Washington, DC, Global Environment Facility Independent Evaluation Office. (http://www.gefieo.org/evaluations/value-money-analysis-gef-interventions-supportsustainable-forest-management-2019)

GEF IEO (2019b), GEF Annual Performance Report 2017, Washington,DC, Global Environment Facility Independent Evaluation Office. (http://www.gefieo.org/evaluations/annualperformance-report-apr-2017)

Goodchild, M.F. (2013), “The quality of big (geo)data”, Dialogues in Human Geography, Vol. 3 No. 3, pp. 280-284.

Hansen, M.C., Potapov, P.V., Moore, R., Hancher, M., Turubanova, S.A., Tyukavina, A., Thau, D., et al. (2013), "High-resolution global maps of 21st-century forest cover change", Science, Vol. 342 No. 6160, pp. 850-853.

Jayachandran, S., Laat, J. de, Lambin, E.F., Stanton, C.Y., Audy, R. and Thomas, N.E. (2017), "Cash for carbon:A randomized trial of payments for ecosystem services to reduce deforestation", Science, Vol. 357 No. 6348, pp. 267-273.

Lech, M., Uitto, J.I., Harten, S., Batra, G. and Anand, A. (2018), "Improving international development evaluation through geospatial data and analysis", International Journal of Geospatial and Environmental Research,Vol. 5 No. 2, available at: https://dc.uwm.edu/ijger/ vol5/iss $2 / 3$.

Melesse, A.M., Weng, Q., S. Thenkabail, P. and Senay, G.B. (2007), "Remote sensing sensors and applications in environmental resources mapping and modelling", Sensors (Basel, Switzerland),Vol. 7 No. 12, pp. 3209-3241.

Minelli, S., Erlewein,A. and Castillo,V. (2017), "Land degradation neutrality and the UNCCD: From political vision to measurable targets", International Yearbook of Soil Law and Policy, 2016, pp. 85-104.

Naidoo, R., Gerkey, D., Hole, D., Pfaff, A., Ellis, A.M., Golden, C.D., Herrera, D., et al. (2019), "Evaluating the impacts of protected areas on human well-being across the developing world”, Science Advances, Vol. 5 No. 4, p. eaav3006.

Renger, R., Cimetta, A., Pettygrove, S. and Rogan, S. (2002), "Geographic information systems (GIS) as an evaluation tool", American Journal of Evaluation,Vol. 23 No. 4, pp. 469-479.

Spitzer, D. (1986), "On applications of remote sensing for environmental monitoring", Environmental Monitoring and Assessment, Vol. 7 No. 3, pp. 263-271. 